\title{
Adverse effects of statins
}

This Editorial (BMJ 2014;348:g3306, doi:10.1136/bmj.g3306) says that the incorrect statement relating to Zhang and colleagues' study appeared in the initial submission from Abramson and colleagues, and that the peer reviewers and editors didn't pick this up. In fact, the reference to Zhang and colleagues was added at a later stage, after peer review and revision, when the editors asked the authors to provide a reference for a statement about the side effects of statins.
As the Editorial correctly states, the revised and edited version was not sent back for further peer review. This is in line with our current process but is something we are revisiting. The full pre-pubication history for the article is available at http://www. bmj.com/content/suppl/2014/05/16/bmj.f6123.DC1

Cite this as: $B M J$ 2014;348:93563

๑ BMJ Publishing Group Ltd 2014 